\title{
Combining Plant Sterols With Walking Lowers Postprandial Triacylglycerol More Than Walking Only in Chinese Men With Elevated Body Mass Index
}

\author{
Ching T. Lye, Swarup Mukherjee, and Stephen F. Burns \\ Nanyang Technological University
}

\begin{abstract}
This study examined if plant sterols and walking reduce postprandial triacylglycerol (TAG) concentrations in Chinese men with elevated body mass index $\left(\geq 23.5 \mathrm{~kg} / \mathrm{m}^{2}\right)$. Fifteen Chinese men (mean [SD]: age $=25$ [3] years and body mass index $=26.2$ [1.5] kg/m ${ }^{2}$ ] completed four 10-day trials in random order with a 7- to 10-day washout between trials: (a) daily consumption of a control margarine while sedentary (C-S), (b) daily consumption of margarine containing $2 \mathrm{~g} /$ day of plant sterols while sedentary (PS-S), (c) daily consumption of a control margarine with 30-min daily walking (C-W), and (d) daily consumption of margarine containing $2 \mathrm{~g}$ /day of plant sterols with 30-min daily walking (PS-W). On Day 11 of each trial, postprandial TAG was measured after a high-fat milkshake. The 5-hr total area under the TAG curve was 22\%, 25\%, and 12\% lower on PS-W (mean [SD]: 8.9 [4.3] mmol.5 hr/L) than C-S (11.4 [4.5] mmol.5 hr/L; $p=.005 ; d=0.56)$, PS-S (11.9 [4.9] mmol.5 hr/L; $p=.004 ; d=0.67)$, and $\mathrm{C}-\mathrm{W}(10.1[4.4] \mathrm{mmol} \cdot 5 \mathrm{hr} / \mathrm{L} ; p=.044 ; d=0.27)$ trials, respectively. Similarly, 5-hr incremental area for PS-W (4.5 [2.7] $\mathrm{mmol} \cdot 5 \mathrm{hr} / \mathrm{L})$ was $31 \%, 32 \%$, and $18 \%$ lower than C-S $(6.6[3.3] \mathrm{mmol} \cdot 5 \mathrm{hr} / \mathrm{L} ; p=.005 ; d=0.62)$, PS-S $(6.6[3.4] \mathrm{mmol} \cdot 5 \mathrm{hr} / \mathrm{L} ; p=.004 ; d=0.64)$, and C-W (5.5 [2.8] mmol.5 hr/L; $p=.032 ; d=0.29)$. Ten days of daily plant sterol intake combined with walking presents an intervention strategy to lower postprandial TAG in Chinese men with elevated body mass index.
\end{abstract}

Keywords: exercise, lipids, phytosterols

Plant sterols (PS) can reduce low-density lipoprotein cholesterol (LDL-c) at intakes of $\sim 2 \mathrm{~g} /$ day (Catapano et al., 2016; Gylling et al., 2014), but accumulating evidence also implicates them in the reduction of fasting triacylglycerol (TAG), with greater reductions seen in individuals with higher TAG (Demonty et al., 2013; Gylling et al., 2014). However, circulating TAG is highest after eating with peak concentrations approximately $4 \mathrm{hr}$ after food intake (Kolovou et al., 2011). Thus, any effect of PS on TAG may be most prominent during the postprandial period. Prospective epidemiological studies associate high nonfasting TAG with cardiovascular events and mortality, and for many individuals it represents the usual metabolic state (Nordestgaard et al., 2007).

Aerobic exercise also reduces fasting (Kraus et al., 2002) and postprandial TAG (Maraki \& Sidossis, 2013). Given both exercise and PS modify TAG, surprisingly only one study has examined their combined benefits noting reductions in fasting TAG along with LDL-c, but the effects were not additive or synergistic compared with the treatments in isolation (Varady et al., 2004).

\footnotetext{
(C) 2019 The Authors. Published by Human Kinetics, Inc. This is an Open Access article distributed under the terms of the Creative Commons Attribution 4.0 International License, CC BY 4.0, which permits unrestricted noncommercial and commercial use, distribution, and reproduction in any medium, provided the original work is properly cited, the new use includes a link to the license, and any changes are indicated. See http://creativecommons.org/licenses/by/4.0. This license does not cover any third-party material that may appear with permission in the article.
}

The authors are with Physical Education and Sports Science Academic Group, National Institute of Education, Nanyang Technological University, Singapore, Singapore. Burns (stephen.burns@nie.edu.sg) is corresponding author.
We are unaware of any studies examining how PS and exercise combined impact postprandial TAG. However, it is hypothesized that aerobic exercise administered after PS intake may synergistically blunt chylomicron entry to the circulation and reduce hepatic lipid transport resulting in lower very low-density lipoprotein (VLDL) release (Marinangeli et al., 2006).

Finally, postprandial TAG is exaggerated in overweight men, even when fasting TAG is normal (Halkes et al., 2001). Moreover, cardiovascular risk factors often present before a body mass index (BMI) of $25 \mathrm{~kg} / \mathrm{m}^{2}$ in Chinese populations (WHO Expert Consultation, 2004), and some recommendations consider PS use even in individuals at intermediate or low cardiovascular disease risk (Catapano et al., 2016; Gylling et al., 2014). However, the efficacy of PS on blood lipids in Chinese is not as strong as for Western populations ( $\mathrm{Li}$ et al., 2007), and no examination has been made of their impact on postprandial TAG in Chinese. Thus, we hypothesized that combining dietary PS supplementation with daily brisk walking could reduce postprandial TAG concentrations in healthy Chinese men with elevated BMI.

\section{Methods}

\section{Participants}

This study received Nanyang Technological University ethical approval (IRB-2013-05-027), and written informed consent was obtained from participants before testing. Recruitment took place through advertisement, and 19 individuals completed screening and were randomized. Inclusion criteria were as follows: male, 21-35 years, Chinese for three generations (participants, parents, and 
grandparents), self-reported stable body mass $( \pm 1.5 \mathrm{~kg})$ in the past 2 months (Wing et al., 2006), BMI of $23.5 \mathrm{~kg} / \mathrm{m}^{2}$ to less than $35 \mathrm{~kg} / \mathrm{m}^{2}$ (WHO Expert Consultation, 2004), reported engaging in structured physical activity $\leq 2$ times per week for $<20$ min per time, fasting TAG of $<1.7 \mathrm{mmol} / \mathrm{L}$; free of cardiovascular disease and diabetes, not dieting, nonsmoker, consuming alcohol $\leq 3$ times per week with $\leq 3$ drinks per time by self-report, not using medication affecting lipid or carbohydrate metabolism, and no injuries restricting walking. The upper fasting TAG level reflected that other than elevated BMI, these men were at intermediate or low cardiovascular risk and improved group homogeneity.

\section{Sample Size Justification}

A priori analyses using $\mathrm{G}^{*}$ Power (version 3.1; Universität Kiel, Kiel, Germany) were powered to detect an effect size $(f)$ of $0.40\left(\eta_{\mathrm{p}}^{2}=.14\right)$ on the 5-hr total postprandial TAG response using a repeatedmeasures analysis of variance (ANOVA) and within-subject design. For one group under four conditions with an alpha level of .05 and correlation among repeated measures of $.5,13$ participants would provide $92 \%$ power to detect differences among conditions.

\section{Anthropometric Measurements}

Stature was measured using an electronic wall-mounted stadiometer (Seca 242; Seca, Hamburg, Germany) to the nearest $0.1 \mathrm{~cm}$, body mass was recorded on a digital scale (Mettler-Toledo ID1Plus; Mettler-Toledo SEA Pte Ltd, Singapore) to the nearest $0.1 \mathrm{~kg}$, and waist circumference was measured at the umbilicus using a flexible measuring tape. A 30- $\mu$ l fingertip blood sample was taken for TAG measurement on a dry chemistry analyzer (Reflotron Plus; Roche Diagnostics, Mannheim, Germany; minimum detection level of $0.8 \mathrm{mmol} / \mathrm{L}$ ) after a 10 -hr overnight fast.

\section{Preliminary Exercise Testing}

Peak oxygen consumption was determined using a modified continuous walking ramp protocol (Balke \& Ware, 1959) set at $6.0-6.5 \mathrm{~km} / \mathrm{hr}$. Initial treadmill gradient was $1 \%$ and increased by $1 \%$ per minute until voluntary exhaustion. Expired air was measured using a metabolic cart (Parvomedics MMS-2400; Parvomedics, Sandy, UT), and heart rate was monitored continuously using short-range telemetry (Polar RS400; Polar, Oulu, Finland). Rating of perceived exertion (RPE; Borg, 1973) was assessed periodically.

\section{Main Trials}

Participants completed four 10-day trials: (a) daily consumption of a control margarine while sedentary (C-S), (b) daily consumption of a margarine containing $2 \mathrm{~g}$ /day of PS while sedentary (PS-S), (c) daily consumption of a control margarine with 30-min daily walking $(\mathrm{C}-\mathrm{W})$, and $(\mathrm{d})$ daily consumption of a margarine containing $2 \mathrm{~g} /$ day of PS with 30-min daily walking (PS-W). Randomization was counterbalanced for the first trials with a random integer set generator used to formulate sequences for the remaining trials. On Day 11, participants came to the laboratory for a measurement of fasting lipids and TAG responses to a high-fat milkshake. There was a 7- to 10-day washout between trials. A 6-week dietary supplementation of $3 \mathrm{~g} /$ day of PS containing mostly $\beta$-sitosterol and campesterol - the major sterols used here-showed a serum half-life of these sterols during washout of $\sim 4$ days (Clifton et al., 2008). Postprandial TAG return to preexercise levels $48-60 \mathrm{hr}$ postexercise (Herd et al., 1998).

\section{Food Intake, Physical Activity, Alcohol, and Body Mass}

Food intake was self-recorded over 2 weekdays and 1 weekend day prior to the first trial and during trials on Days 3, 6, and 10 using a diary. Participants curtailed physical activities, beyond those of daily living, for each trial and refrained from alcohol. Body mass was measured fasted on Days 1 and 11 of each trial.

\section{Days 1-10}

On Day 1, of all trials, participants reported to the laboratory at 08:00. A fasting blood sample was taken into a 6-ml potassium EDTA vacutainers $^{\text {TM }}$ (Becton Dickinson and Co., Franklin Lakes, NJ). Participants were given their margarines to take away for consumption over 10 days. On C-W and PS-W, participants completed a 30-min treadmill walk each day. On Day 10, participants standardized their food consumption and ate one of two standardized evening meals $\left(\mathrm{McChicken}^{\circledR}\right.$, French Fries, and Coca-Cola ${ }^{\circledR}$ : 4.1 MJ, protein: $20 \mathrm{~g}$, fat: $37 \mathrm{~g}$, and carbohydrate: $143 \mathrm{~g}$ or FiletO-Fish ${ }^{\circledR}$, French Fries, and Coca-Cola ${ }^{\circledR}: 3.9$ MJ, protein: 20 g, fat: $33 \mathrm{~g}$, and carbohydrate: $138 \mathrm{~g}$ ) by 21:00. Purchases were repeated on subsequent trials, validated, and reimbursed. Participants then fasted overnight, consuming only water ad libitum.

\section{Margarines}

Margarines were prepared, formulated, and donated by a local industrial supplier (Lam Soon Group, Singapore). Participants consumed $25 \mathrm{~g}$ /day of control or PS (Vegapure ${ }^{\circledR} 95 \mathrm{FF}$; free sterol composition by area: $\beta$-sitosterol $=49 \%$, campesterol $=25 \%$, stigmasterol $=18 \%$ ) margarine on Days $1-10$ (Table 1). The PS margarine had a PS ester content of $14 \%$, estimated to provide $\sim 2 \mathrm{~g}$ PS per day assuming a coefficient of conversion from PS ester to PS of 0.6. Supplementation of $25 \mathrm{~g}$ of soybean oil-based spread providing $1.6 \mathrm{~g}$ of PS with $\beta$-sitosterol $(46.1 \%)$ and campesterol $(26.6 \%)$ can increase serum concentrations of these sterols within 7 days (Clifton et al., 2008). Participants were blind to the supplementation order. Margarines were aliquoted into containers, each with $25 \mathrm{~g}$, by a dietitian. Participants were free to consume the margarines within their normal daily food intake pattern and not restricted to a time. They were advised on how to incorporate them into their diet, including spreading or mixing with food items but not frying or cooking, by the dietitian. Consumption of margarines was verified to a research team member daily.

\section{Walking}

On C-W and PS-W trials, participants completed a 30-min supervised daily treadmill walk at a speed and gradient equivalent to

\section{Table 1 Energy and Fat Content of the Control and Plant Sterol Margarines}

\begin{tabular}{lcc}
\hline & $\begin{array}{c}\text { Control } \\
\text { per } \mathbf{1 0 0} \mathbf{~ g}\end{array}$ & $\begin{array}{c}\text { Plant sterol } \\
\text { per 100 g }\end{array}$ \\
\hline Energy (MJ) & 2.03 & 1.96 \\
Energy from fat (MJ) & 2.01 & 1.94 \\
Saturated fat (g) & 13.1 & 12.0 \\
Monounsaturated fat (g) & 25.1 & 22.7 \\
Polyunsaturated fat (g) & 14.8 & 16.6 \\
Trans fat (g) & 0.2 & 0.2 \\
\hline
\end{tabular}


$50 \%$ peak oxygen consumption. Heart rate and RPE were recorded during walking. Time of day for walking was catered to fit around each participant's daily life.

\section{Day 11}

Participants reported to the laboratory at 08:00, and a cannula was inserted into a forearm vein. A fasting blood sample was collected 10 min later. Participants then consumed a high-fat milkshake (ice-cream, milk, and cream) providing $1.21 \mathrm{~g}$ of fat, $0.62 \mathrm{~g}$ of carbohydrate, $0.29 \mathrm{~g}$ of protein, and $61 \mathrm{~kJ}$ of energy per kilogram of body mass within 10 min. Further blood samples were collected $1-5 \mathrm{hr}$ postconsumption. While in the laboratory, participants read, worked, listened to music, or rested.

\section{Analytical Methods}

Blood samples were collected into precooled 6-ml potassium EDTA vacutainers $^{\mathrm{TM}}$ (Becton Dickinson and Co.) and centrifuged at $1,000 \times g$ for $15 \mathrm{~min}$. Plasma was analyzed for TAG, total cholesterol, and high-density lipoprotein cholesterol (HDL-c) on an automated analyzer (Abbott Architect c4000; Abbott Diagnostics, Chicago, IL). Within- and between-batch coefficient of variation were $<2 \%$. The Friedewald formula was used to calculate LDL-c (Friedewald et al., 1972).

\section{Statistics}

Data were analyzed using SPSS version 23.0 (IBM, Chicago, IL). TAG and body mass data were non-normally distributed and log transformed. Paired $t$ tests were used to compare mean heart rate and RPE during walking trials. Preintervention data and summary postprandial TAG measures on Day 11 were compared among trials using one-way ANOVA. Two-way ANOVA was used to examine changes among trials and over time. ANOVA was followed by planned contrasts to examine differences between interventions. These are reported along with $95 \%$ confidence intervals (CIs) of the differences and effect sizes (Cohen's $d$ ). Significance was set at $p<.05$. Data are presented as mean (SD).

\section{Results}

\section{Participants}

Of 19 individuals randomized, three withdrew because of time commitments or unsuccessful cannulation and one was unable to comply with instructions related to fasting and excluded. Thus, 15 participants were included in the analysis (Table 2).

Table 2 Physical Characteristics of the Participants

\begin{tabular}{lcc}
\hline & $\boldsymbol{n}=\mathbf{1 5}$ & Range \\
\hline Age (years) & $25(3)$ & $21-33$ \\
Height $(\mathrm{m})$ & $1.74(0.07)$ & $1.66-1.89$ \\
Body mass $(\mathrm{kg})$ & $79.8(9.1)$ & $69.6-100.7$ \\
BMI $\left(\mathrm{kg} / \mathrm{m}^{2}\right)$ & $26.2(1.5)$ & $23.5-29.0$ \\
Umbilical waist circumference $(\mathrm{cm})$ & $88.9(6.4)$ & $80.8-100.0$ \\
Fasting TAG $(\mathrm{mmol} / \mathrm{L})$ & $1.1(0.3)$ & $<0.8-1.7$ \\
Maximal oxygen uptake $(\mathrm{mL} / \mathrm{kg} / \mathrm{min})$ & $36.1(4.9)$ & $29.3-48.6$ \\
\hline
\end{tabular}

Note. Values are presented as mean (SD). BMI= body mass index; TAG = triacylglycerol.

\section{Body Mass and Dietary Intake}

Body mass did not differ among trials on Day $1(p=.221)$ or Day $11(p=.154)$ or change during trials (interaction, $p=.520$ ). Preintervention energy intake (Day 1: 7.7 [2.4] MJ; Day 2: 7.5 [2.7] MJ; Day 3: 7.8 [2.3] MJ, $p=.858$ ), intake of protein (Day 1: 78 [31] g; Day 2: 85 [25] g; Day 3: 75 [18] g, $p=.442)$, carbohydrate (Day 1: 234 [65] g; Day 2: 211 [64] g; Day 3: 246 [84] g, $p=.240$ ), and fat (Day 1: 66 [28] g; Day 2: 67 [41] g; Day 3: 66 [28] g, $p=.958$ ) were similar over 3 days. The preintervention energy and macronutrient intake were similar to the intakes reported during trials (all $p \mathrm{~s}>.05$ ) with no differences among trials (data not shown; all $p s>.05$ ).

\section{Walking}

Average heart rate (C-W: 139 [12] beats per min vs. PS-W: 136 [12] beats per min; $p=.304$ ) and RPE (C-W: 10 [2] vs. PS-W: 10 $[2] ; p=.954)$ during walking over 10 days were similar between exercise trials.

\section{Fasting Lipid Concentrations on Day 1 and Day 11}

Fasting lipids (Table 3) did not differ among trials on Day 1 (all $p \mathrm{~s}>.05)$. Changes in fasting TAG differed among trials and over time (interaction, $p=.006$ ) increasing on PS-S compared with reductions on C-W $(p=.019)$ and PS-W $(p=.031)$. This pattern of response was similar for TAG:HDL ratio between Days 1 and 11 (interaction, $p=.023$ ), but contrasts could not identify where the difference occurred. No changes in other lipids were noted (all $p$ s > .05). One-way ANOVA based on trial order showed no differences in fasting TAG on Day $1(p=.810)$ or Day $11(p=.902)$.

\section{Summary TAG Responses on Day 11}

The 5-hr total (main effect of trial, $p=.001$; Figure 1a) and incremental (main effect of trial, $p=.001$; Figure $1 \mathrm{~b}$ ) areas under the curve differed among trials. For total area, PS-W was 22\%, 25\%, and $12 \%$ lower than C-S $(d=0.56,95 \%$ CI $[-0.189,-0.041])$, PS-S $(d=0.67,95 \%$ CI $[-0.213,-0.049])$, and C-W $(d=0.27,95 \% \mathrm{CI}$ $[-0.114,0.009])$, respectively. Similarly, the 5-hr incremental area with PS-W was $31 \%, 32 \%$, and $18 \%$ lower than C-S $(d=0.62,95 \%$ CI $[-0.258,-0.086])$, PS-S $(d=0.64,95 \%$ CI $[-0.301,-0.055])$, and C-W $(d=0.29,95 \%$ CI $[-0.168,0.005])$ trials, respectively. The 5-hr total and incremental area were also lower after C-W than C-S by $11 \%$ and $17 \%$, respectively (both $d \mathrm{~s}>0.29$ ). Peak TAG (main effect of trial, $p=.002$ ) was $26 \%, 29 \%$, and $17 \%$ lower on PS-W than C-S $(d=0.60,95 \%$ CI $[-0.158,-0.033]) ;$ PS-S $(d=0.70,95 \%$ CI $[-0.178,-0.037]) ;$ and C-W $(d=0.36,95 \%$ CI $[-0.099,-0.002])$ trials, respectively (Figure 1c). One-way ANOVA for trial order showed no differences in TAG total $(p=.676)$ or incremental $(p=.463)$ area or peak TAG $(p=.696)$.

To understand the independent effects of the walking and PS, a two-way ANOVA was conducted for all TAG summary measures (Varady et al., 2004). A main effect of exercise was observed for all summary measures $(p<.05)$ but no independent effect of sterols (all $p \mathrm{~s}>.05)$.

\section{Postprandial TAG concentrations on Day 11}

There were significant main effects for trial $(p=.001)$, time $(p<.001)$, and an interaction $(p=.032)$ for 5 -hr postprandial TAG on Day 11 (Figure 2). Circulating TAG was lower across the postprandial period on the PS-W than the C-S and PS-S trials and 
Table 3 Fasting Lipid Concentrations on Day 1 and Day 11 of Each Trial

\begin{tabular}{|c|c|c|c|c|}
\hline & \multicolumn{4}{|c|}{ Trial } \\
\hline & C-S & PS-S & C-W & PS-W \\
\hline \multicolumn{5}{|c|}{ TAG $(\mathrm{mmol} / \mathrm{L})$} \\
\hline Day 1 & $0.98(0.34)$ & $0.89(0.20)$ & $0.96(0.27)$ & $1.12(0.36)$ \\
\hline Day 11 & $0.94(0.33)$ & $0.97(0.32)$ & $0.86(0.31)$ & $0.82(0.35)$ \\
\hline$\Delta$ & $-0.04(0.29)$ & $0.08(0.28)$ & $-0.10(0.26)$ & $-0.30(0.43)^{*}$ \\
\hline \multicolumn{5}{|c|}{ Total cholesterol (mmol/L) } \\
\hline Day 1 & $4.49(0.60)$ & $4.62(0.66)$ & $4.51(0.65)$ & $4.65(0.76)$ \\
\hline Day 11 & $4.31(0.61)$ & $4.28(0.66)$ & $4.26(0.68)$ & $4.20(0.70)$ \\
\hline$\Delta$ & $-0.19(0.36)$ & $-0.34(0.31)$ & $-0.25(0.41)$ & $-0.44(0.28)$ \\
\hline \multicolumn{5}{|c|}{ LDL-c (mmol/L) } \\
\hline Day 1 & $2.81(0.58)$ & $2.96(0.66)$ & $2.84(0.57)$ & $2.90(0.67)$ \\
\hline Day 11 & $2.70(0.57)$ & $2.65(0.59)$ & $2.66(0.60)$ & $2.62(0.60)$ \\
\hline$\Delta$ & $-0.10(0.35)$ & $-0.31(0.34)$ & $-0.18(0.35)$ & $-0.29(0.24)$ \\
\hline \multicolumn{5}{|c|}{ HDL-c (mmol/L) } \\
\hline Day 1 & $1.24(0.12)$ & $1.25(0.18)$ & $1.24(0.18)$ & $1.23(0.13)$ \\
\hline Day 11 & $1.18(0.17)$ & $1.19(0.13)$ & $1.21(0.15)$ & $1.21(0.17)$ \\
\hline$\Delta$ & $-0.07(0.13)$ & $-0.06(0.10)$ & $-0.02(0.09)$ & $-0.02(0.11)$ \\
\hline \multicolumn{5}{|c|}{ Non-HDL-c (mmol/L) } \\
\hline Day 1 & $3.25(0.56)$ & $3.37(0.67)$ & $3.28(0.59)$ & $3.41(0.73)$ \\
\hline Day 11 & $3.13(0.61)$ & $3.09(0.63)$ & $3.05(0.63)$ & $2.99(0.66)$ \\
\hline$\Delta$ & $-0.12(0.30)$ & $-0.28(0.32)$ & $-0.23(0.35)$ & $-0.42(0.28)$ \\
\hline \multicolumn{5}{|c|}{ TChol:HDL-c } \\
\hline Day 1 & $3.63(0.48)$ & $3.76(0.79)$ & $3.70(0.60)$ & $3.78(0.62)$ \\
\hline Day 11 & $3.72(0.75)$ & $3.61(0.61)$ & $3.54(0.55)$ & $3.50(0.63)$ \\
\hline$\Delta$ & $0.09(0.39)$ & $-0.15(0.38)$ & $-0.16(0.24)$ & $-0.28(0.35)$ \\
\hline \multicolumn{5}{|c|}{ LDL-c:HDL-c } \\
\hline Day 1 & $2.27(0.48)$ & $2.43(0.72)$ & $2.33(0.52)$ & $2.36(0.55)$ \\
\hline Day 11 & $2.35(0.67)$ & $2.23(0.52)$ & $2.21(0.49)$ & $2.18(0.55)$ \\
\hline$\Delta$ & $0.08(0.32)$ & $-0.19(0.38)$ & $-0.12(0.23)$ & $-0.18(0.29)$ \\
\hline \multicolumn{5}{|c|}{ TAG:HDL-c } \\
\hline Day 1 & $0.79(0.29)$ & $0.73(0.24)$ & $0.81(0.29)$ & $0.92(0.32)$ \\
\hline Day 11 & $0.82(0.35)$ & $0.83(0.34)$ & $0.73(0.30)$ & $0.70(0.33)$ \\
\hline$\Delta$ & $0.03(0.32)$ & $0.10(0.25)$ & $-0.08(0.23)$ & $-0.22(0.40)^{*}$ \\
\hline
\end{tabular}

Note. Values are presented as mean (SD). Day 1: $n=13$, Day 11: $n=15$, and $\Delta: n=13$. C-S $=$ control margarine and sedentary; PS-S $=$ plant sterol margarine and sedentary; $\mathrm{C}-\mathrm{W}=$ control margarine with walking; PS-W = plant sterol margarine with walking; TAG $=$ triacylglycerol; LDL-c $=$ low-density lipoprotein cholesterol; HDL-c $=$ highdensity lipoprotein cholesterol; TChol = total cholesterol; ANOVA = analysis of variance.

*Two-way ANOVA interaction Day 1 to Day $11(p<.05)$.

from 3 to 5 hr than the C-W trial. For the C-W trial, TAG was lower than C-S 2-3 hr after the milkshake.

\section{Discussion}

Aerobic exercise and PS are hypothesized to synergistically blunt postprandial TAG (Marinangeli et al., 2006). In this study, 10 days of daily walking reduced the 5 -hr incremental TAG area by $\sim 17 \%$ in Chinese men with elevated BMI, confirming previous observations (Maraki \& Sidossis, 2013). However, when PS was combined with walking, the reduction increased to $\sim 32 \%$. Other summary measures support this and demonstrate that, as hypothesized, TAG was reduced in the postprandial period when at its peak.

Two studies have investigated the effects of PS on postprandial TAG (Baumgartner et al., 2016; Demonty et al., 2006).
Combining PS ( $1.7 \mathrm{~g} /$ day for 4 weeks) with fish oils in hyperlipidemic individuals reduced postprandial TAG more than fish oils alone, although the independent effect of the PS was not elucidated and only an isolated 4-hr postprandial measure taken (Demonty et al., 2006). The second study found no reduction in postprandial TAG after 4 weeks of PS supplementation ( $3 \mathrm{~g} /$ day) in individuals with normal fasting TAG (Baumgartner et al., 2016). The conflicting findings may relate to the background TAG/lipid levels of participants. However, like the current investigation, the second study included an independent PS trial and with this study's data suggest that PS do not reduce postprandial TAG in isolation.

Circulating TAG is transported in intestinal-derived chylomicrons and hepatic-derived VLDL and reflects a balance in the rate of appearance and clearance of these particles (Malkova \& Gill, 2006). Exercise can improve lipoprotein lipase affinity for TAG 

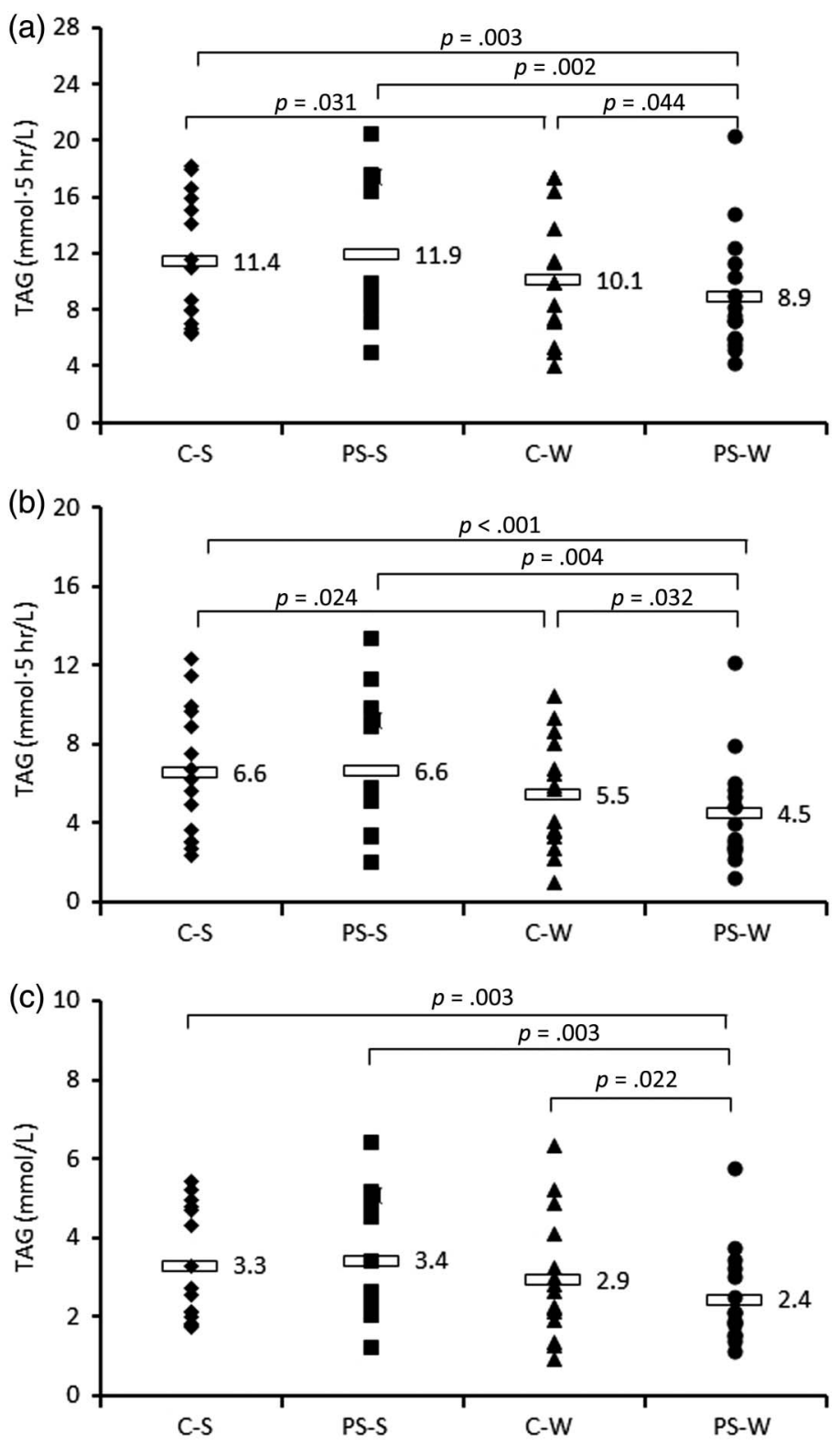

Figure 1 - Mean (open rectangles) and individual concentrations for the 5-hr total (a) and incremental (b) area under the TAG concentration versus time curve and peak TAG concentration (c) on Day 11 of the trials. $\mathrm{TAG}=$ triacylglycerol; $\mathrm{C}-\mathrm{S}=$ control margarine and sedentary; PS-S = plant sterol margarine and sedentary; $\mathrm{C}-\mathrm{W}=$ control margarine with walking; PS-W = plant sterol margarine with walking. Main effects of trial from one-way analysis of variance for total $(p=.001)$ and incremental $(p=.001)$ area under the curve and peak TAG $(p=.001)$.

hydrolysis, particularly in VLDL (Ghafouri et al., 2015), while PS can reduce plasma and hepatic TAG by interfering in intestinal fatty acid absorption (Rideout et al., 2010). While walking alone reduced postprandial TAG in our investigation, no reduction was seen with PS. However, some studies show reduced VLDL with PS or stanols without changes in overall circulating TAG (Plat \& Mensink, 2009; Schonewille et al., 2014). This may explain why TAG was unaffected by PS alone, but for the combined intervention, lower VLDL with PS improved TAG clearance to a greater extent than walking alone.

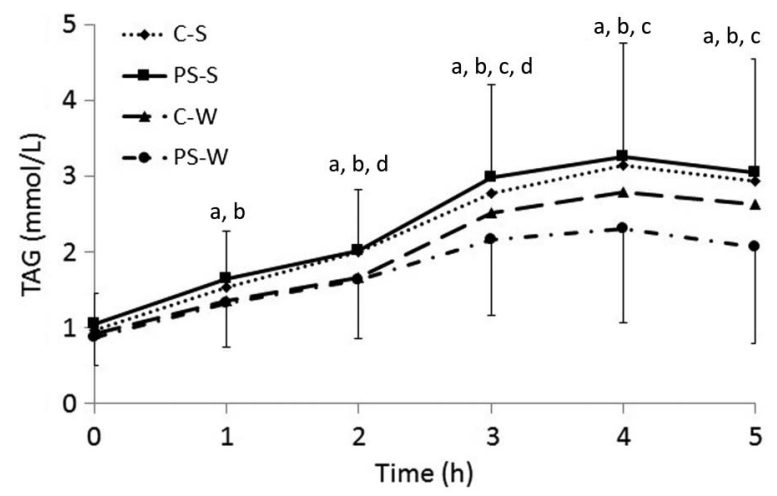

Figure 2 - Mean (SD) TAG concentrations on Day 11 of the C-S, PS-S, C-W, and PS-W trials. TAG = triacylglycerol; C-S = control margarine and sedentary; PS-S = plant sterol margarine and sedentary; $\mathrm{C}-\mathrm{W}=$ control margarine with walking; $\mathrm{PS}-\mathrm{W}=$ plant sterol margarine with walking. Main effect of trial $(p=.001)$, main effect of time $(p<.001)$, and Trial $\times$ Time interaction $(p=.032)$. ${ }^{\mathrm{a}} \mathrm{C}-\mathrm{S}$ versus PS-W $(p<.05) .{ }^{b}$ PS-S versus PS-W $(p<.05) .{ }^{\mathrm{c}} \mathrm{C}-\mathrm{W}$ versus PS-W $(p<.05) .{ }^{\mathrm{d}} \mathrm{C}-\mathrm{S}$ versus $\mathrm{C}-\mathrm{W}(p<.05)$.

Pooled analysis from 12 investigations in 935 hypercholesterolemic individuals provided 1.6-2.5 g/day of PS found a mean lowering of serum fasting TAG of $\sim 6 \%$, with the largest decreases in individuals with the highest TAG (Demonty et al., 2013). In comparison with $\mathrm{C}-\mathrm{S}$, we did not observe any change in fasting TAG, or other blood lipids, with PS in isolation or when combined with walking. The normal lipid profiles of participants may explain why no change occurred along with the shorter period of supplementation (Demonty et al., 2006; Varady et al., 2004). Alternatively, the impact of PS on fasting lipids in Chinese may not be as great as in Western populations (Li et al., 2007). However, we also note that the intervention was not designed/powered to observe fasting lipid changes.

The within-subject randomized design is a study strength. Evaluation of PS on postprandial TAG in Chinese participants with elevated BMI is novel given that the efficacy of PS on blood lipids in Chinese is not as strong as for Western populations ( $\mathrm{Li}$ et al., 2007) but that some public health recommendations advocate their use even in individuals at low or moderate cardiovascular risk. Several limitations exist including the previously mentioned short supplementation period. Nevertheless, supplementation with a comparable dose and type of PS as used here substantially elevated serum concentrations within a similar time scale (Clifton et al., 2008). However, we did not measure serum PS and cannot confirm the changes over the trials or associate them with changes in postprandial TAG. Similarly, serum PS concentrations after each washout period are uncertain, although washout time should have been sufficient (Clifton et al., 2008) and no trial order effects were noted. We did also not objectively measure physical activity outside of laboratory testing, control the time of exercise training, or conduct postprandial testing on Day 1 of each intervention. Potentially, physical activity or lifestyle habits could change over time affecting TAG concentrations, although no trial order effects were noted. Finally, these findings need verifying in older adults and individuals of different ethnic backgrounds where the response to exercise (Arjunan et al., 2013) or PS (Varady et al., 2004) may differ.

In conclusion, 10 days of daily walking reduces postprandial TAG, but further reductions are achieved with consumption of $2 \mathrm{~g} /$ day of PS in healthy Chinese men with elevated BMI. 


\section{Novelty Statement}

This study demonstrates a novel strategy to lower postprandial TAG by combining daily PS with exercise.

\section{Practical Applications}

Individuals spend much of their day with elevated TAG. Consuming PS with moderate-intensity exercise represents a simple, achievable strategy to help control TAG levels.

\section{Acknowledgments}

The authors acknowledge that this work was supported by BASF through their Newtrition ${ }^{\circledR}$ Asia Research Grant. The plant sterols used in the study was Vegapure ${ }^{\circledR}$ 95FF, supplied by BASF. They also thank Lam Soon Group for their kind donations of the margarines used in the present study. They thank all volunteers for their participation in this study. The authors declare that they have no conflicts of interest to report. S.F. Burns formulated the research questions. S.F. Burns and S. Mukherjee obtained study funding and were responsible for study design. S.F. Burns and C.T. Lye were responsible for all data collection and analysis. All authors were involved in preparation and review of the manuscript and accept full responsibility for its contents.

\section{References}

Arjunan, S.P., Bishop, N.C., Reischak-Oliveira, A., \& Stensel, D.J. (2013). Exercise and coronary heart disease risk markers in South Asian and European men. Medicine \& Science in Sports \& Exercise, 45(7), 1261-1268. PubMed ID: 23470315 doi:10.1249/MSS. 0b013e3182853ecf

Balke, B., \& Ware, R.W. (1959). An experimental study of "physical fitness" of air force personnel. United States Armed Forces Medical Journal, 10(6), 675-688. PubMed ID: 13659732

Baumgartner, S., Mensink, R.P., \& Plat, J. (2016). Effects of a plant sterol or stanol enriched mixed meal on postprandial lipid metabolism in healthy subjects. PLoS ONE, 11(9), e0160396. PubMed ID: 27611192 doi:10.1371/journal.pone.0160396

Borg, G.A. (1973). Perceived exertion: A note on history and methods. Medicine and Science in Sports, 5(2), 90-93. PubMed ID: 4721012

Catapano, A.L., Graham, I., De Backer, G., Wiklund, O., Chapman, M.J., Drexel, H., . . . Zamorano, J.L. (2016). 2016 ESC/EAS guidelines for the management of dyslipidaemias: The task force for the management of dyslipidaemias of the European Society of Cardiology (ESC) and European Atherosclerosis Society (EAS) developed with the special contribution of the European Association for Cardiovascular Prevention \& Rehabilitation (EACPR). Atherosclerosis, 253, 281-344. PubMed ID: 27594540 doi:10.1016/j.atherosclerosis.2016.08.018

Clifton, P.M., Mano, M., Duchateau, G.S., van der Knaap, H.C., \& Trautwein, E.A. (2008). Dose-response effects of different plant sterol sources in fat spreads on serum lipids and C-reactive protein and on the kinetic behavior of serum plant sterols. European Journal of Clinical Nutrition, 62(8), 968-977. PubMed ID: 17538539 doi:10. 1038/sj.ejen.1602814

Demonty, I., Chan, Y.M., Pelled, D., \& Jones, P.J. (2006). Fish-oil esters of plant sterols improve the lipid profile of dyslipidemic subjects more than do fish-oil or sunflower oil esters of plant sterols. The American Journal of Clinical Nutrition, 84(6), 1534-1542. PubMed ID: 17158440 doi:10.1093/ajcn/84.6.1534
Demonty, I., Ras, R.T., van der Knaap, H.C., Meijer, L., Zock, P.L., Geleijnse, J.M., \& Trautwein, E.A. (2013). The effect of plant sterols on serum triglyceride concentrations is dependent on baseline concentrations: A pooled analysis of 12 randomised controlled trials. European Journal of Nutrition, 52(1), 153-160. PubMed ID: 22252793 doi:10.1007/s00394-011-0297-x

Friedewald, W.T., Levy, R.I., \& Fredrickson, D.S. (1972). Estimation of the concentration of low-density lipoprotein cholesterol in plasma, without use of the preparative ultracentrifuge. Clinical Chemistry, 18(6), 499-502. PubMed ID: 4337382

Ghafouri, K., Cooney, J., Bedford, D.K., Wilson, J., Caslake, M.J., \& Gill, J.M. (2015). Moderate exercise increases affinity of large very low-density lipoproteins for hydrolysis by lipoprotein lipase. The Journal of Clinical Endocrinology \& Metabolism, 100(6), 2205-2213. PubMed ID: 25867814 doi:10.1210/jc.20151196

Gylling, H., Plat, J., Turley, S., Ginsberg, H.N., Ellegard, L., Jessup, W., ... European Atherosclerosis Society Consensus Panel on Phytosterols. (2014). Plant sterols and plant stanols in the management of dyslipidaemia and prevention of cardiovascular disease. Atherosclerosis, 232(2), 346-360. PubMed ID: 24468148 doi:10.1016/j. atherosclerosis.2013.11.043

Halkes, C.J., Castro Cabezas, M., van Wijk, J.P., \& Erkelens, D.W. (2001). Gender differences in diurnal triglyceridemia in lean and overweight subjects. International Journal of Obesity and Related Metabolic Disorders, 25(12), 1767-1774. PubMed ID: 11781756 doi:10.1038/ sj.ijo.0801831

Herd, S.L., Hardman, A.E., Boobis, L.H., \& Cairns, C.J. (1998). The effect of 13 weeks of running training followed by $9 \mathrm{~d}$ of detraining on postprandial Lipaemia. The British Journal of Nutrition, 80(1), 57-66. PubMed ID: 9797644 doi:10.1017/S0007114598001779

Kolovou, G.D., Mikhailidis, D.P., Kovar, J., Lairon, D., Nordestgaard, B.G., Ooi, T.C., . . Panotopoulos, G. (2011). Assessment and clinical relevance of non-fasting and postprandial triglycerides: An expert panel statement. Current Vascular Pharmacology, 9(3), 258-270. PubMed ID: 21314632 doi:10.2174/157016111795495549

Kraus, W.E., Houmard, J.A., Duscha, B.D., Knetzger, K.J., Wharton, M.B., McCartney, J.S., . . Slentz, C.A. (2002). Effects of the amount and intensity of exercise on plasma lipoproteins. The New England Journal of Medicine, 347(19), 1483-1492. PubMed ID: 12421890 doi:10.1056/NEJMoa020194

Li, N.Y., Li, K., Qi, Z., Demonty, I., Gordon, M., Francis, L., . . Neal, B.C. (2007). Plant sterol-enriched milk tea decreases blood cholesterol concentrations in Chinese adults: A randomised controlled trial. The British Journal of Nutrition, 98(5), 978-983. PubMed ID: 17617940 doi:10.1017/S0007114507754302

Malkova, D., \& Gill, J.M. (2006). Effects of exercise on postprandial lipoprotein metabolism. Future Lipidology, 1(6), 743-755. doi:10. 2217/17460875.1.6.743

Maraki, M.I., \& Sidossis, L.S. (2013). The latest on the effect of prior exercise on postprandial lipaemia. Sports Medicine, 43, 463-481. PubMed ID: 23580393 doi:10.1007/s40279-013-0046-9

Marinangeli, C.P., Varady, K.A., \& Jones, P.J. (2006). Plant sterols combined with exercise for the treatment of hypercholesterolemia: Overview of independent and synergistic mechanisms of action. The Journal of Nutritional Biochemistry, 17(4), 217-224. PubMed ID: 16410048 doi:10.1016/j.jnutbio.2005.09.003

Nordestgaard, B.G., Benn, M., Schnohr, P., \& Tybjaerg-Hansen, A. (2007). Nonfasting triglycerides and risk of myocardial infarction, ischemic heart disease, and death in men and women. The Journal of the American Medical Association, 298(3), 299-308. PubMed ID: 17635890 doi:10.1001/jama.298.3.299 
Plat, J., \& Mensink, R.P. (2009). Plant stanol esters lower serum triacylglycerol concentrations via a reduced hepatic VLDL-1 production. Lipids, 44(12), 1149-1153. PubMed ID: 19856194 doi:10.1007/ s11745-009-3361-z

Rideout, T.C., Harding, S.V., \& Jones, P.J. (2010). Consumption of plant sterols reduces plasma and hepatic triglycerides and modulates the expression of lipid regulatory genes and de novo lipogenesis in C57BL/6J mice. Molecular Nutrition \& Food Research, 54(S1), S7-S13. doi:10.1002/mnfr.201000027

Schonewille, M., Brufau, G., Shiri-Sverdlov, R., Groen, A.K., \& Plat, J. (2014). Serum TG-lowering properties of plant sterols and stanols are associated with decreased hepatic VLDL secretion. Journal of Lipid Research, 55(12), 2554-2561. PubMed ID: 25348863 doi:10.1194/ jlr.M052407
Varady, K.A., Ebine, N., Vanstone, C.A., Parsons, W.E., \& Jones, P.J. (2004). Plant sterols and endurance training combine to favorably alter plasma lipid profiles in previously sedentary hypercholesterolemic adults after 8 wk. The American Journal of Clinical Nutrition, 80(5), 1159-1166. PubMed ID: 15531661 doi:10.1093/ajcn/80.5.1159

WHO Expert Consultation. (2004). Appropriate body-mass index for Asian populations and its implications for policy and intervention strategies. The Lancet, 363(9403), 157-163. doi:10.1016/S01406736(03)15268-3

Wing, R.R., Tate, D.F., Gorin, A.A., Raynor, H.A., \& Fava, J.L. (2006). A self-regulation program for maintenance of weight loss. The New England Journal of Medicine, 355(15), 1563-1571. PubMed ID: 17035649 doi:10.1056/NEJMoa061883 


\section{Erratum: Lye, Mukherjee, and Burns (2019)}

When this article was originally published, it was published with the copyright assigned to Human Kinetics, Inc. Since publication, the authors have chosen to publish the article under the Creative Commons Attribution 4.0 International License. The copyright is now as follows:

(C) 2019 The Authors. Published by Human Kinetics, Inc. This is an Open Access article distributed under the terms of the Creative Commons Attribution 4.0 International License, CC BY 4.0, which permits unrestricted noncommercial and commercial use, distribution, and reproduction in any medium, provided the original work is properly cited, the new use includes a link to the license, and any changes are indicated. See http://creativecommons.org/licenses/by/4.0. This license does not cover any third-party material that may appear with permission in the article. 